\title{
Karakteristik Tingkat Okupansi dan Komposisi Barang Bawaan pada Perjalanan Berpenumpang pada Taksi Bluebird di Kota Surabaya
}

\author{
Occupancy Level and Bagage Composition Characteristics on \\ Ocupied Trip of Bluebird Taxi in Surabaya City
}

\author{
Merlyn Mangopo $^{1 \mathrm{a})}$ \& Hitapriya Suprayitno ${ }^{\mathbf{1 b})}$ \\ ${ }^{1)}$ Departemen Teknik Sipil, Institut Teknologi Sepuluh Nopember (ITS), Surabaya.
}

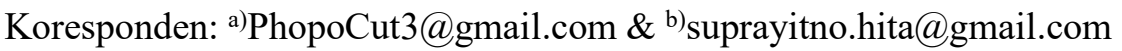

\begin{abstract}
ABSTRAK
Pertumbuhan kawasan-kawasan terbangun di Kota Surabaya memberikan potensi yang besar bagi pengemudi taksi untuk mengangkut lebih banyak penumpang dari kawasan satu ke kawasan lain. Namun saat ini perusahaan dan pengemudi taksi belum efisien dan efektif dalam menggunakan kendaraan taksi untuk mengangkut penumpang, dikarenakan mereka belum mengetahui dengan tepat ukuran dan jenis taksi yang berpotensi untuk mengangkut penumpang lebih efektif. Dan belum bisa memperkirakan besar kecilnya bagasi suatu kendaraan taksi yang efisien digunakan dalam mengangkut penumpang. Oleh karena itu dalam penelitian ini melakukan metode analisis distribusi data dengan penyebaran kuesioner dan diolah dalam bentuk tabel dan grafik. Hasil penelitian ini adalah jumlah penumpang terjadi sebanyak 1237 perjalanan taksi atau $82 \%$. Jumlah penumpang sebanayak 2 terjadi sebanyak 231 perjalanan taksi atau $15 \%$. Jumlah penumpang sebanyak 3 terjadi sebanyak 28 perjalanan taksi atau 2\%. Dan jumlah penumpang sebanyak 4 terjadi sebanyak 7 perjalanan taksi atau $1 \%$. Tipe bawaan barang dengan komposisi Besar terjadi pada 190 perjalanan taksi sebesar 13\%. Tipe bawaan barang dengan komposisi Sedang terjadi pada 271 perjalanan taksi sebesar 18\%. Dan Tipe bawaan barang dengan Komposisi Kecil terjadi pada 1042 perjalanan taksi sebesar 69\%. Data Karakteristik tingkat okupansi dan komposisi bawaan barang bias digunakan unutk menentukan kapasistas taksi di Surabaya. Usaha Taksi di Surabaya cukup dengan menggunakan mobil taksi yang kecil dengan ruang bagasi kecil.
\end{abstract}

Kata Kunci: manajemen fasilitas, perjalanan taksi, metode analisis distribusi data, tingkat okupansi, komposisi bawaan barang, kota Surabaya

\section{PENDAHULUAN}

Perkembangan Jumlah penduduk di Kota Surabaya dari tahun ke tahun semakin bertambah yaitu tahun 2019 mencapai 3.095.026 jiwa (BPS Kota Surabaya, 2019), hal ini berpengaruh terhadap perluasan kawasan terbangun kota sehingga aktivitas masyarakat dan kebutuhan akan transportasi juga semakin meningkat. Layanan Angkutan Taksi, sebagai fasilitas perkotaan, harus direncanakan dengan baik. Hal-hal yang harus direncanakan antara lain adalah : ukuran armada taksi, system operasi taksi, fasilitas tempat tunggu taksi, dan yang lain. Perencanaan dan perangan harus mengikuti prinsip Manajemen Aset Infrastruktur dan Fasilitas (Soemitro \& Suprayitno, 2018; Suprayitno \& Soemitro, 2018).

Kota Surabaya memerlukan taksi yang beroperasi secara optimal, walaupun pelayanan taksi menyerupai kendaraan pribadi. Hal ini dikarenakan sebagian masyarakat nyaman menggunakan angkutan umum non trayek seperti taksi, masyarakat yang dimaksud yaitu 
masyarakat menengah keatas. Oleh karena itu jumlah taksi yang beroperasi harus dikendalikan oleh pemerintah setempat.

Karakteristik mengenai pengguna jasa dan karakteristik perjalanan angkutan umum merupakan salah satu pengetahuan karakteristik utama dalam suatu perencanaan sistem angkutan umum (Suprayitno, Irlambang Pramono \& Wibowo, 2006). Layanan Angkutan Umum BRT dan KA perlu merencanakan sistem layanan operasional dengan baik agar bisa menjalankan fungsinya sebagai angkutan perkotaan yang modern. Untuk itu prediksi jumlah penumpang potensial perlu di perhitungkan dalam penentuan ukuran bus dan frekwensi layanan yang akan dioperasikan, sebagai salah satu komponen perencanaan sistem layanan operasional (Susanti, Soemitro \& Suprayitno, 2017; Suprayitno \& Ryansyah, 2018; Suprayitno \& Upa, 2016; Upa, Suprayitno \& Ryansyah, 2018). Selain itu dalam perencanaan transportasi perlu memahami perilaku pola distribusi panjang perjalanan (TLD) untuk mendapatkan model transportasi suatu wilayah secara baik (Suprayitno, Ratnasari \& Saraswati, 2018).

Karakteristik tingkat okupansi dan komposisi bawaan barang perjalanan taksi belum terlalu diperhatikan. Sehingga perusahaan pengemudi taksi belum mengetahui ukuran, jenis dan bagasi yang efisien dan cocok untuk pengangkutan penumpang taksi di kota Surabaya.

Pengoptimalan pengangkutan taksi penting memperhatikan tingkat okupansi dan komposisi bawaan barang penumpang perjalanan taksi, untuk memudahkan perusahaan dan pengemudi taksi mengetahui ukuran jenis taksi beserta dengan bagasinya.

Oleh karena itu perlu dilakukan penelitian ini untuk mengetahui karakteristik tingkat okupansi dan komposisi tipe bawaan barang perjalanan taksi di kota Surabaya, agar perusahaan dan pengemudi lebih mudah dan efektif dalam penyediaan armada taksi yang sesuai bagi pengangkutan penumpang di Surabaya.

\section{STUDI PUSTAKA}

\section{Definisi Angkutan Umum}

Angkutan umum penumpang (AUP) adalah angkutan penumpang yang dilakukan dengan sistem sewa atau bayar. Termasuk dalam pengertian angkutan umum penumpang adalah bus, kereta api, angkutan air dan angkutan udara (Warpani, 1990).

\section{Definisi Angkutan Umum Non Trayek}

Angkutan yang tidak terikat dengan trayek, biasanya angkutan ini melakukan pelayanan dari rumah ke rumah (Vuchic, 1981). Angkutan kendaraan umum ini terdiri dari :

- Pengangkutan dengan menggunakan taksi, merupakan pelayanan angkutan dari pintu ke pintu dalam wilayah operasi terbatas.

- Pengangkutan dengan cara sewa, merupakan pelayanan dari pintu ke pintu dengan atau tanpa pengemudi dalam wilayah operasi terbatas. Contohnya car rentals.

- Pengangkutan untuk keperluan parwisata, merupakan pelayanan angkutan ke dan dari daerah-daerah tujuan wisata.

Ciri-ciri pelayanan angkutan orang dengan taksi:

- Tidak berjadwal.

- Dilayani oleh mobil penumpang yang dilengkapi dengan argometer.

- Pelayanannya dari pintu ke pintu.

\section{Defenisi Taksi}

Taksi merupakan salah satu jenis layanan transport yang mempunyai karateristik pelayanan khusus, yang merupakan perpaduan antara kendaraan pribadi dan angkutan umum (Levinson \& Weant, 1982 dikutip oleh Junaedi, 2006). 


\section{Okupansi Perjalanan Taksi}

Okupansi merupakan perbandingan prosentase antara panjang perjalanan taksi, isi penumpang dengan total panjang perjalanan taksi berpenumpang maupun taksi kosong (Tamin, 1997 dikutip oleh Guntur \& Yusandy, 2016). Hubungan tingkat okupansi suatu angkutan terhadap kondisi pelayanan angkutan seperti yang terlihat dalam Tabel 1:

Tabel 1. Hubungan Tingkat Okupansi Terhadap Tingkat Kondisi Pelayanan Angkutan

\begin{tabular}{ccc}
\hline No & Okupansi (\%) & Kondisi Pelayanan \\
\hline 1 & 100 & Sangat Baik \\
2 & 80 & Baik \\
3 & 60 & Sedang \\
4 & 40 & Kurang \\
5 & 20 & Kurang baik \\
6 & 0 & Tidak Ada \\
\hline
\end{tabular}

(Sumber: Peraturan Direktur Jenderal Perhubungan Darat Nomor: SK.1905/KP.801/DRJD/2010)

\section{Microsoft Excel}

Microsoft excel adalah software microsoft yang digunakan untuk mengolah data, terutama yang berhubungan dengan angka. Secara garis besar formula pada aplikasi excel adalah suatu persamaan matematika untuk menghitung nilai-nilai tertentu dengan tujuan mendapatkan hasil yang diharapkan (TLWK, 2017).

\section{METODA PENELITIAN}

Penelitian awal mengidetifikasi masalah dan studi literatur mengenai tingkat okupansi dan komposisi bawaan barang penumpang perjalanan taksi. Kemudian melakukan survei pendahuluan untuk mengetahui kondisi langsung di lapangan dan keadaan taksi yang berpotensi untuk diteliti.

Pengumpulan data-data untuk proses analisis yaitu data primer yang diperoleh dari survey langsung dengan sebaran kuesioner dan wawancara langsung terhadap responden, dan data sekunder diperoleh dari instansi-instansi atau pihak pihak terkait.

Penentuan jumlah sampel menggunakan rumus slovin (Sevilla et.al,1960:182) dengan nilai kelonggaran ketidaktelitian $\mathrm{e}=10 \%=0,1$. Sehingga jumlah sampel berjumlah 97 atau 100 pengemudi dari 2710 populasi taksi Bluebird.

Data-data yang didapatkan dari survei kuesioner dan wawancara kemudian dianalisis dengan analisis distribusi data dan diolah dengan tabel dan grafik (Akdon \& Riduwan, 2005), yang menunjukan persentase nilai panjang perjalanan taksi dan variasi volume perjalanan taksi selama 24 jam.

\section{PENGUMPULAN DATA}

Metode yang digunakan pada metoda analisis distribusi data perhitungan karakteristik tingkat okupansi dan komposisi bawaan barang penumpang taksi adalah pengumpulan data sekunder terkait literatur dan pengumpulan data primer terkait proses pendataan jumlah penumpang yang menggunakan taksi dan ukuran bawaan barang penumpang perjalanan taksi. Pada pengumpulan data primer dilakukan pengamatan secara langsung di area kota Surabaya yang meliputi Surabaya Timur, Surabaya Barat, Surabaya Utara, Surabaya Selatan dan Surabaya Pusat dengan membagikan kuesioner kepada pengemudi taksi Bluebird untuk mengetahui pendataan jumlah penumpang yang menggunakan taksi dan ukuran bawaan barang yang dibawanya, dijadikan acuan atau dasar dalam mengerjakan metoda analisis distribusi data. 


\section{ANALISIS PENELITIAN}

\section{Rekapitulasi Variasi Tingkat Okupansi Penumpang Taksi Bluebird}

Berdasarkan hasil survei penyebaran kuisioner kepada 100 responden pengemudi taksi BlueBird diperoleh 1503 perjalanan taksi yang terdiri 298 perjalanan untuk Surabaya Timur, 257 perjalanan untuk Surabaya Barat, 315 perjalanan untuk Surabaya Utara, 336 perjalanan untuk Surabaya Selatan dan 297 perjalanan untuk Surabaya Pusat. selama 1 minggu. Dengan variasi jumlah penumpang dari 1- 4 orang. Untuk rekapitulasi variasi tingkat okupansi penumpang taksi Bluebird dapat dilihat pada Tabel 2.

Tabel 2. Rekapitulasi Variasi Tingkat Okupansi Penumpang Taksi Bluebird

\begin{tabular}{cccccc}
\hline $\begin{array}{c}\text { Jumlah } \\
\text { Penumpang } \\
\text { (Orang) }\end{array}$ & \multicolumn{6}{c}{$\begin{array}{c}\text { PERSENTASE BANYAKNYA PERJALANAN TAKSI } \\
\text { Surabaya } \\
\text { Timur } \\
(\%)\end{array}$} & $\begin{array}{c}\text { Surabaya } \\
\text { Barat } \\
(\%)\end{array}$ & $\begin{array}{c}\text { Surabaya } \\
\text { Utara } \\
(\%)\end{array}$ & $\begin{array}{c}\text { Surabaya } \\
\text { Selatan } \\
(\%)\end{array}$ & $\begin{array}{c}\text { Surabaya } \\
\text { Pusat } \\
(\%)\end{array}$ \\
\hline 1 & 78 & 82 & 87 & 82 & 82 \\
2 & 17 & 14 & 12 & 16 & 17 \\
3 & 4 & 2 & 1 & 2 & 1 \\
4 & 1 & 2 & 0 & 0 & 0 \\
\hline Total & $\mathbf{1 0 0 \%}$ & $\mathbf{1 0 0 \%}$ & $\mathbf{1 0 0 \%}$ & $\mathbf{1 0 0 \%}$ & $\mathbf{1 0 0 \%}$ \\
\hline
\end{tabular}

Dari tabel diatas memperlihatkan bahwa jumlah penumpang 1 orang paling banyak menggunakan taksi untuk perjalanannya yaitu pada Surabaya Timur sebesar $78 \%$, Surabaya Barat sebesar $82 \%$, Surabaya Utara sebesar $87 \%$, Surabaya Selatan sebesar $82 \%$ dan Surabaya Pusat sebesar 82\%. Untuk lebih jelasnya dapat dilihat pada Gambar 1.

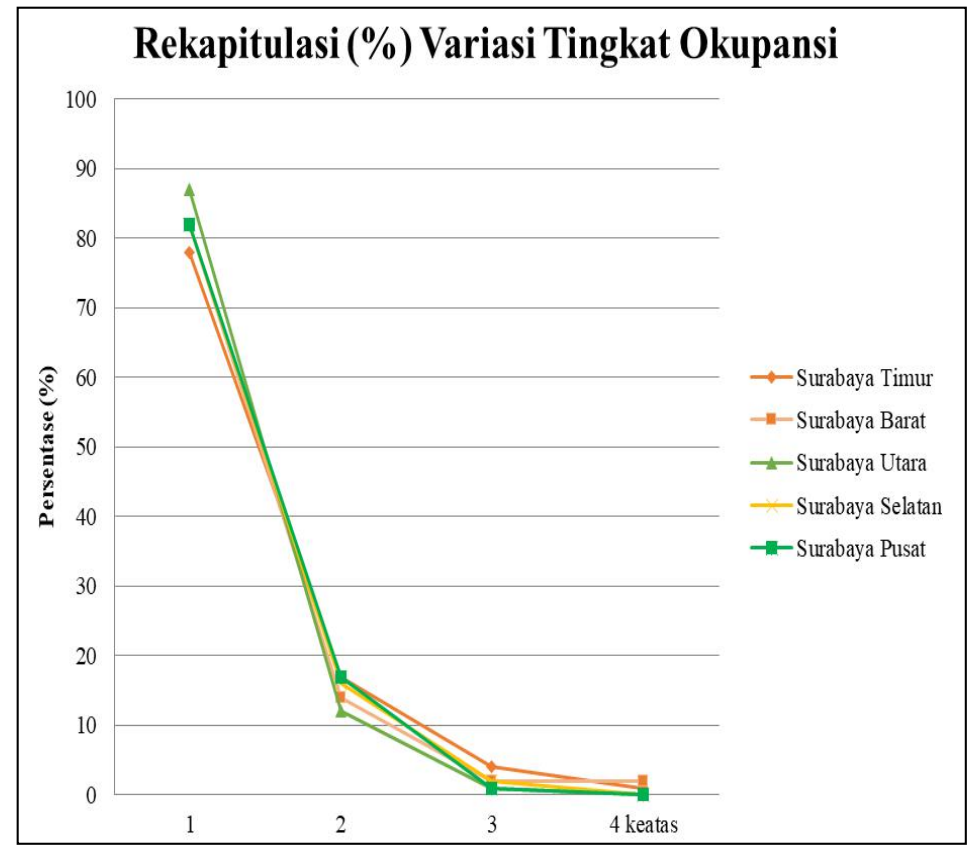

Gambar 1. Grafik Rekapitulasi Variasi Tingkat Okupansi penumpang taksi Bluebird 


\section{Variasi Tingkat Okupansi Surabaya}

Pada Kota Surabaya rata-rata tingkat okupansi penumpang yaitu 1,2, dengan variasi jumlah penumpang terbanyak melakukan perjalanan adalah pada jumlah penumpang 1 orang sebanyak $82 \%$ dan variasi jumlah penumpang paling sedikit melakukan perjalanan adalah pada penumpang 4 orang sebanyak $1 \%$. Variasi tingkat okupansi penumpang taksi di Kota Surabaya untuk lebih jelas dapat dilihat pada Tabel 3 dan Gambar 2.

Tabel 3. Variasi Tingkat Okupansi Penumpang Kota Surabaya

\begin{tabular}{ccc}
\hline $\begin{array}{c}\text { Jumlah Penumpang } \\
\text { (Orang) }\end{array}$ & $\begin{array}{c}\text { Banyaknya Perjalanan } \\
\text { (Perjalanan/minggu) }\end{array}$ & $\begin{array}{c}\text { Persentase } \\
(\mathbf{\%})\end{array}$ \\
\hline 1 & 1237 & 82 \\
2 & 231 & 15 \\
3 & 28 & 2 \\
4 & 7 & 1 \\
\hline Total & $\mathbf{1 5 0 3}$ & $\mathbf{1 0 0}$ \\
\hline Rata-rata & $\mathbf{1 , 2}$ & \\
\hline
\end{tabular}

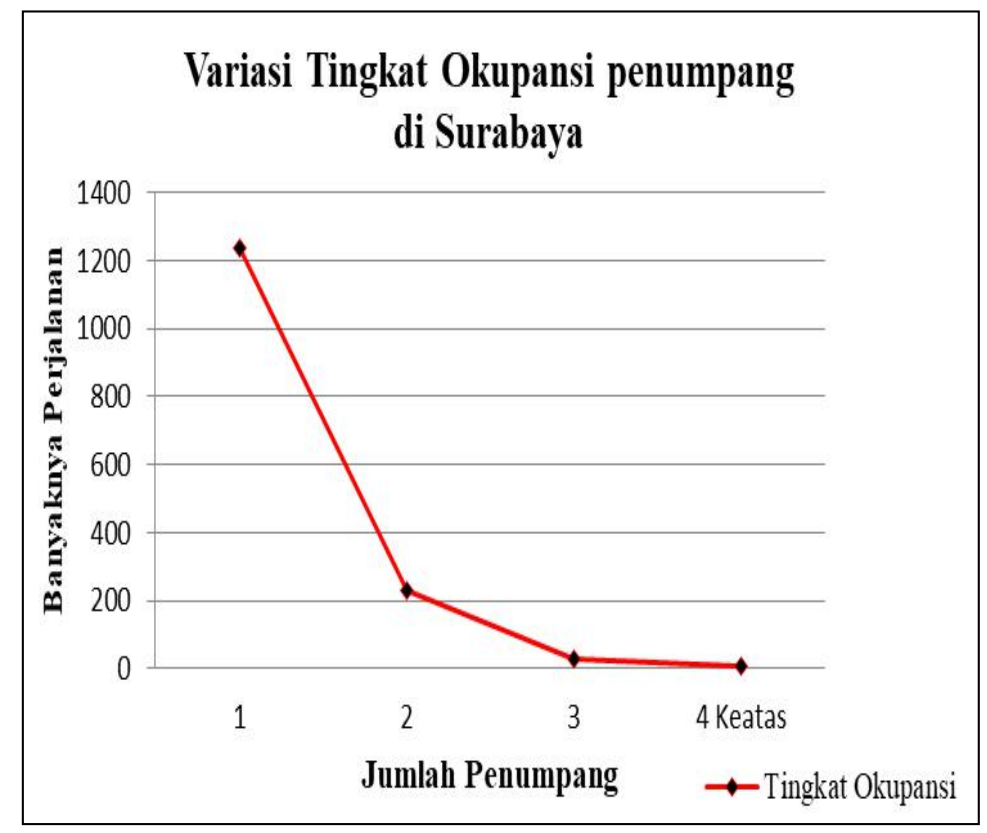

Gambar 2. Grafik Variasi Tingkat Okupansi Surabaya

Pada tabel dan grafik di atas memperlihatkan bahwa jumlah 1 penumpang sebanyak 1237 perjalanan taksi yang terjadi. Jumlah 2 penumpang sebanyak 231 perjalanan taksi yang terjadi. Jumlah 3 penumpang sebanyak 28 perjalanan taksi yang terjadi dan jumlah 4 penumpang sebanyak 7 perjalanan taksi yang terjadi, dengan total perjalanan sebanyak 1503 perjalanan taksi.

\section{Komposisi Tipe Bawaan Barang Penumpang}

Berdasarkan hasil survei penyebaran kuisioner kepada 100 responden pengemudi taksi BlueBird diperoleh 1503 perjalanan, dengan komposisi tipe bawaan barang yaitu ukuran Kecil, Sedang, dan Besar, dan rata-rata komposisi tipe bawaan barang penumpang berukuran 
kecil. Untuk ukuran kecil berukuran sekitar 1- $46 \mathrm{~cm}$, ukuran sedang sekitar 47- $66 \mathrm{~cm}$ dan ukuran besar sekitar 67-74 cm, untuk lebih jelas dapat dilihat pada Gambar 3.

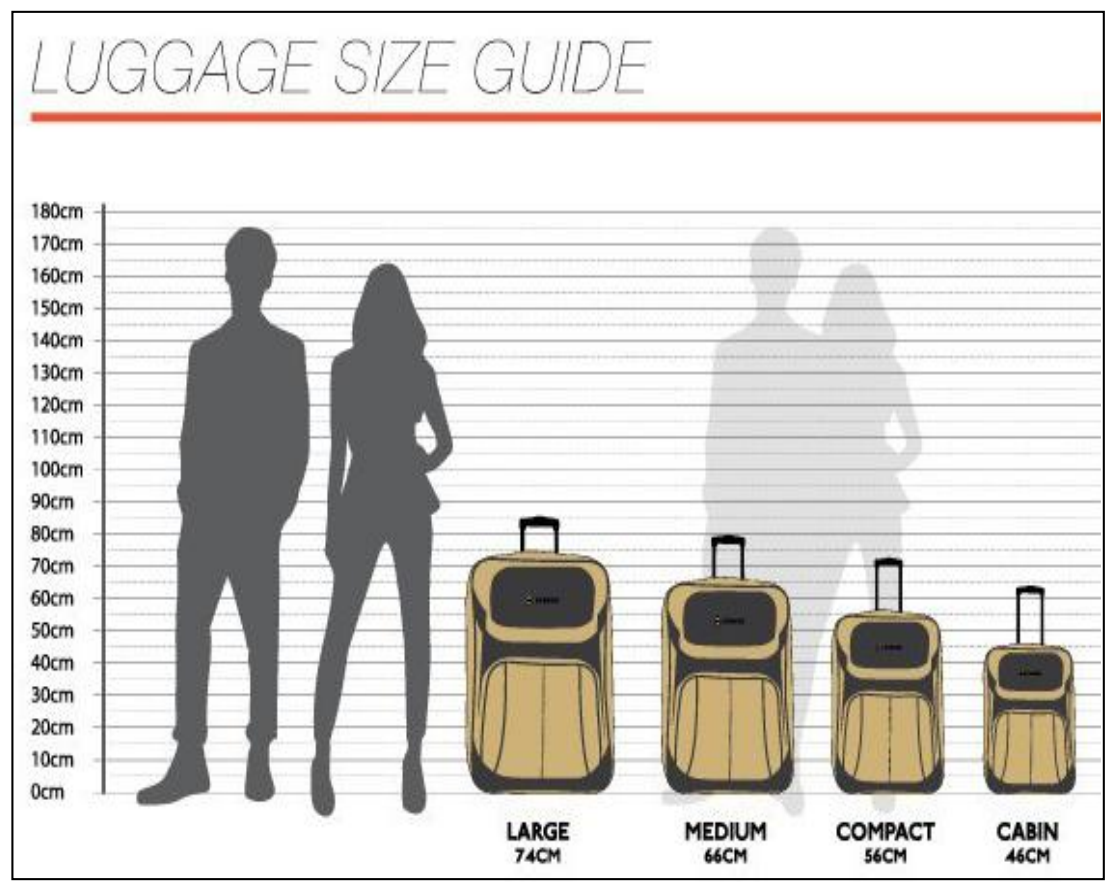

Gambar 3. Jenis Ukuran Bawaan Barang

(Sumber: everme.com, online store)

\section{Rekapitulasi Data Komposisi Tipe Bawaan Barang Penumpang Taksi}

Berdasarkan standar ukuran bawaan barang di atas, maka dibuat rekapitulasi data dapat dilihat pada Tabel 4.dan Gambar 4.

Tabel 4. Rekapitulasi Komposisi Tipe Bawaan Barang penumpang Taksi

\begin{tabular}{cccccc}
\hline $\begin{array}{c}\text { Tipe Bawaan } \\
\text { Barang Besar/ } \\
\text { Sedang/Kecil }\end{array}$ & \multicolumn{6}{c}{ PERSENTASE BANYAKNYA PERJALANAN TAKSI } \\
\hline & $\begin{array}{c}\text { Surabaya } \\
\text { Timur } \\
(\%)\end{array}$ & $\begin{array}{c}\text { Surabaya } \\
\text { Barat } \\
(\%)\end{array}$ & $\begin{array}{c}\text { Surabaya } \\
\text { Utara } \\
(\%)\end{array}$ & $\begin{array}{c}\text { Surabaya } \\
\text { Selatan } \\
(\%)\end{array}$ & $\begin{array}{c}\text { Surabaya } \\
\text { Pusat } \\
(\%)\end{array}$ \\
\hline Besar & 14 & 12 & 5 & 17 & 15 \\
Sedang & 31 & 29 & 3 & 13 & 17 \\
Kecil & 55 & 59 & 92 & 70 & 68 \\
\hline Total & $\mathbf{1 0 0 \%}$ & $\mathbf{1 0 0 \%}$ & $\mathbf{1 0 0 \%}$ & $\mathbf{1 0 0 \%}$ & $\mathbf{1 0 0 \%}$ \\
\hline
\end{tabular}

Pada tabel diatas memperlihatkan bahwa tipe bawaan barang yang paling banyak adalah tipe bawaan barang dengan ukuran Kecil yaitu pada Surabaya Timur sebesar 55\%, pada Surabaya Barat sebesar 59\%, pada Surabaya Utara sebesar 92\%, pada Surabaya Selatan sebesar 70\% dan pada Surabaya Pusat sebesar 68\%. Untuk tipe bawaan barang dengan ukuran sedang yaitu pada Surabaya Timur sebesar 31\%, pada Surabaya barat sebesar 29\%, pada Surabaya Utara sebesar 3\%, pada Surabaya Selatan sebesar 13\% dan pada Surabaya Pusat sebesar 17\%. Untuk tipe bawaan barang dengan ukuran Besar yaitu pada Surabaya Timur sebesar $14 \%$, pada Surabaya Barat sebesar 12\%, pada Surabaya Utara sebesar 5\%, pada 
Surabaya Selatan sebesar 17\% dan pada Surabaya Pusat sebesar 15\%. Untuk lebih jelasnya dapat dilihat pada Gambar 4 sebagai berikut.

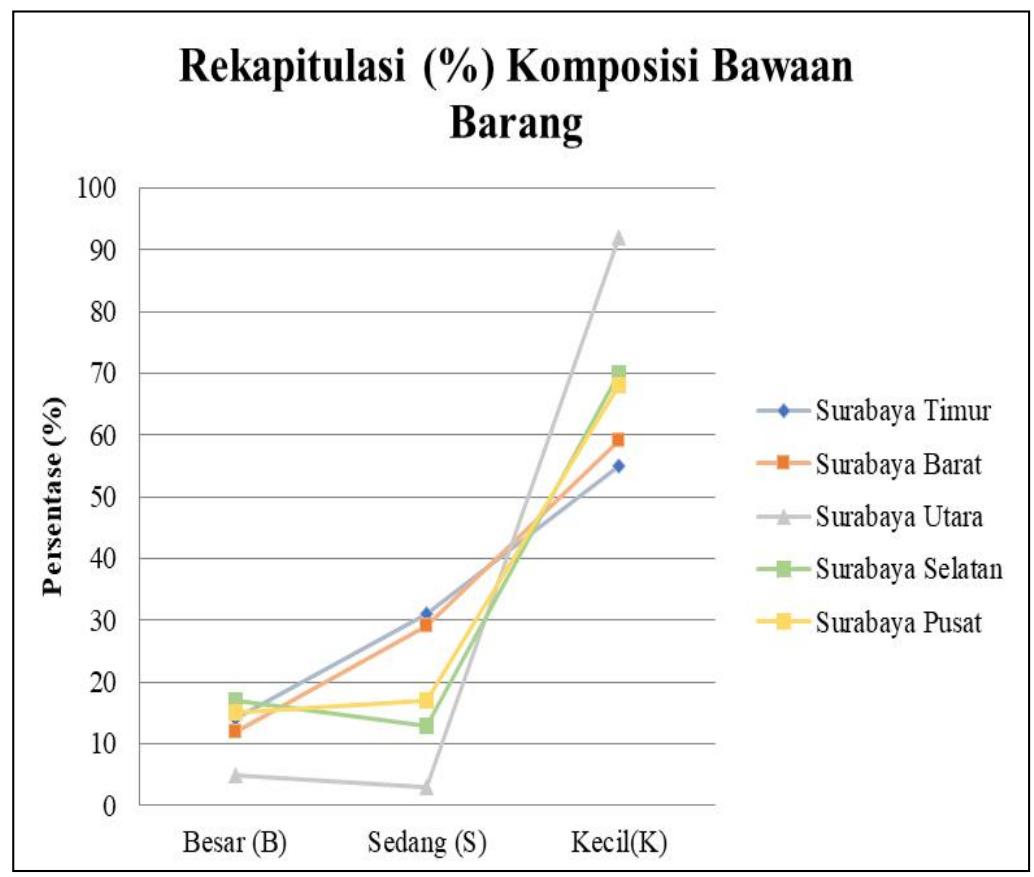

Gambar 4. Grafik Rekapitulasi Komposisi Tipe Bawaan Barang Penumpang Taksi

\section{Komposisi Tipe Bawaan Barang di Surabaya}

Pada Kota Surabaya jumlah bawaan barang terbanyak pada tipe bawaan barang Kecil sebanyak 1042 perjalanan taksi yaitu 69\%. Dan jumlah bawaan barang paling sedikit pada tipe ukuran Besar sebanyak 190 perjalanan taksi yaitu 13\%. Komposisi Tipe bawaan barang penumpang taksi di Surabaya untuk lebih jelas dapat dilihat pada Tabel 5 dan Gambar 5.

Tabel 5. Komposisi Tipe Bawaan Barang di Surabaya

\begin{tabular}{ccc}
\hline $\begin{array}{c}\text { Tipe Bawaan Barang } \\
\text { Besar /Sedang /Kecil }\end{array}$ & $\begin{array}{c}\text { Jumlah } \\
\text { (Barang/minggu) }\end{array}$ & $\begin{array}{c}\text { Persentase } \\
\mathbf{( \% )}\end{array}$ \\
\hline Besar & 190 & 13 \\
Sedang & 271 & 18 \\
Kecil & 1042 & 69 \\
\hline Total & $\mathbf{1 5 0 3}$ & $\mathbf{1 0 0}$ \\
\hline
\end{tabular}

Pada tabel di atas memperlihatkan bahwa tipe ukuran bawaan barang Besar sebanyak 190 perjalanan taksi yaitu 13\%. Tipe ukuran bawaan barang Sedang sebanyak 271 perjalanan taksi yaitu 18\%. Dan tipe ukuran bawaan barang Kecil sebanyak 1042 perjalanan taksi yaitu $69 \%$. Untuk lebih jelasnya dapat dilihat pada Gambar 5. 


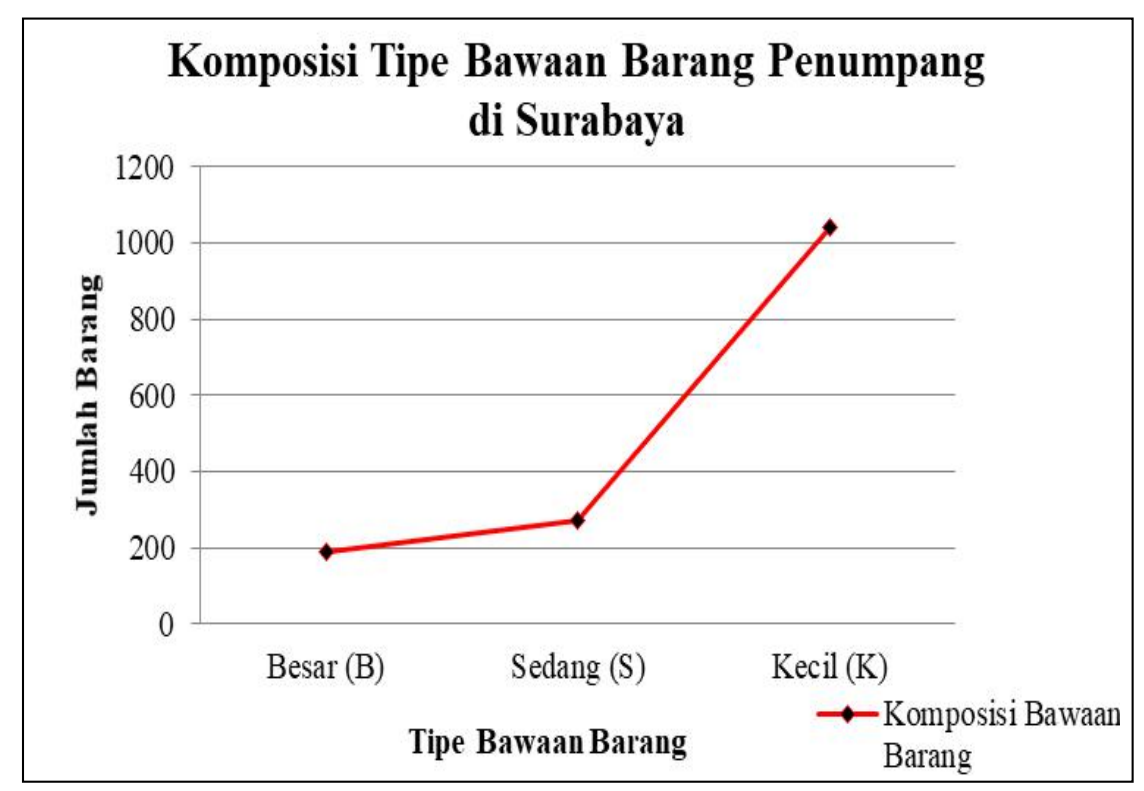

Gambar 5. Grafik Komposisi Tipe Bawaan Barang di Surabaya

\section{KESIMPULAN}

Berdasarkan data hasil pembahasan terkait dengan penelitian ini, maka dapat ditarik beberapa kesimpulan sebagai berikut:

- Tingkat okupansi penumpang taksi Buebird di Surabaya bervariasi sebesar $82 \%$ untuk 1 penumpang dan 15\% untuk 2 penumpang. Sehingga kapasitas taksi Bluebird di Surabaya cukup dengan menggunakan mobil taksi yang kecil.

- Penumpang dengan bawaan barang berukuran kecil berjumlah 69\% dan bawaan barang berukuran sedang berjumlah 18\%. Sehingga bagasi untuk taksi Bluebird di Surabaya relatif menggunakan bagasi kecil atau bahkan tidak membutuhkan bagasi.

CATATAN. Penelitian ini dilakukan dengan pengamatan langsung di seluruh wilayah bagian kota Surabaya terkait dengan pendataan jumlah penumpang yang menggunakan taksi dan tipe ukuran barang bawaan yang dibawanya. Hasil pengamatan dijadikan dasar dalam penelitian metoda analisis distribusi data yang menentukan jenis ukuran taksi dan bagasi yang di perlukan secara efektif dan efisien.

\section{DAFTAR PUSTAKA}

Akdon \& Riduwan. (2005). Rumus dan Data Dalam Aplikasi Statistik. Penerbit Andi. Alfabeta. Bandung.

BPS Kota Surabaya. (2019). Badan Pusat Statistik Surabaya. Surabaya.

Guntur, C.P. \& Yusandy, A. (2016). "Analisis Supplay Demand Angkutan Taksi di Kota Medan Berdasarkan Tingkat Okupansi dan Biaya Operasional Kendaraan”. Jurnal Teknik Sipil USU, Vol. 3, No. 1, Maret 2014.

Junaedi, S. (2006). Efisiensi Industri Jasa Taksi di Kota Semarang. Tesis. Semarang: Universitas Diponegoro.

Slovin. (1960). Menentukan Jumlah Sampel Dengan Rumus Slovin. (Sevilla Et. Al,1960:182).

Soemitro, R.A.A. \& Suprayitno, H. (2018). "Pemikiran Awal Tentang Konsep Dasar Manajemen Aset Fasilitas". Jurnal Manajemen Aset Infrastruktur \& Fasilitas, Vol. 2, Sup. 1, Juni 2018, hal. 1-13.

Suprayitno, H., Irlambang, D., Pramono, Y.A. \& Wibowo, A.G. (2006). "Karakterisik Penumpang dan Perjalanan Pada KA Penumpang Ekonomi di Wilayah Gerbangkertosusila". Jurnal Teknobisnis, Vol. 2, No. 1, Juli 2006, Hal. 41-48. 
Suprayitno, H., Ratnasari, V. \& Saraswati, N. (2018). "Behavior of Trip Length Distribution Pattern due to the Variation of Trip Length Interval Determination". IPTEK, Journal of Engineering, Vol. 4, No. 1, April 2018, Hal. 7-11.

Suprayitno, H. \& Ryansyah, M. (2018). "Karakterisik Pelaku dan Perilaku Perjalanan Penumpang Bus Trans Koetaradja". Jurnal Aplikasi Teknik Sipil, Vol. 16, No. 2, Agustus 2018, Hal. 55-62.

Suprayitno, H. \& Soemitro, R.A.A. (2018). "Preliminary Reflexion on Basic Principle of Infrastructure Asset Management”. Jurnal Manajemen Aset Infrastruktur \& Fasilitas, Vol. 2, No. 1, Maret 2018, Hal. 1-9.

Suprayitno, H. \& Upa, V.A. (2016). "Mamminasata BRT User Trip Characteristics for the Design of Demand Modelling Method for a New BRT Line". IPTEK, The Journal of Technology and Science, Vol. 27, No. 3, Desember 2016, Hal. 47-52.

Susanti, A; Soemitro, R.A.A. \& Suprayitno, H. (2017). "Identifikasi Awal Layanan Angkutan Kereta Api untuk Perjalanan Orang di Kota Surabaya". REKATS - Rekayasa Teknik Sipil, Vol. 1, No. 1, 2017, Hal. : 332-335.

Tamin, Ofyar, Z. (2000). Perencanaan dan Permodelan Transportasi. Penerbit Institut Teknologi Bandung. Bandung.

TLWK. (2017). Kamus Lengkap Formula \& Fungsi Excel. Tim Litbang Wahana Komputer. Penerbit Andi \& Penerbit Wahana Komputer. Yogyakarta \& Semarang.

Upa, V.A., Suprayitno, H. \& Ryansyah, M. (2018). "Perbandingan dan Sintesis Karakterisitik Perilaku Perjalanan Pengguna Bis Trans Mamminasata dan Bis Trans Koetaradja". Jurnal Manajemen Aset Infrastruktur \& Fasilitas, Vol. 2, No. 2, September 2018, Hal. 69-81.

Vuchic, V, R. (1981). Urban Public Transportation Syestem and Technology. Prentice-Hall, Inc, Englewood Cliffs, New Jersey.

Warpani, S. (1990). Merencanakan Sistem Pengangkutan. Penerbit ITB. Bandung. 
(e)ISSN 2615-1847 (p)ISSN 2615-1839

Jurnal Manajemen Aset Infrastruktur \& Fasilitas - Vol. 3, Sup. 2, Desember 2019 